"This is an Author's Accepted Manuscript of an article published in Economics of Energy \& Environmental Policy, Vol. 3, No. 2, 2014, available online at http://dx.doi.org/10.5547/2160-5890.3.2.pdea" 


\section{Irish and British electricity prices: what recent history implies for future prices}

Paul Deane, ${ }^{a}$ John FitzGerald, ${ }^{\text {b,c }}$ Laura Malaguzzi Valeri, ${ }^{\text {b,ce }}$ Aidan Tuohy ${ }^{\mathrm{d}}$ and Darragh Walsh ${ }^{\mathrm{b}, \mathrm{c}}$

a. Energy Policy and Modelling Group, Environmental Research Institute, University College Cork

b. Economic and Social Research Institute, Dublin

c. Department of Economics, Trinity College Dublin

d. Electric Power Research Institute, Knoxville, TN

e. Corresponding author: Economic and Social Research Institute; Whitaker Square, Sir John Rogerson’s Quay; Dublin 2; Ireland. laura.malaguzzivaleri@esri.ie; tel. +3531863 2000. 


\title{
Irish and British electricity prices: what recent history implies for future prices
}

\begin{abstract}
This paper compares retail and wholesale electricity prices in SEM, the market of the island of Ireland, and BETTA in Great Britain. Estimated wholesale costs are much lower in BETTA. We show that this is mostly because the wholesale price in BETTA is set too low to cover generation costs, although it is compensated by large retail margins. The need for substantial new investment in generation in Great Britain suggests that returns to generators will have to increase. This should be accompanied by a decrease in retail margins to avoid overburdening final consumers. Renewable support in Great Britain appears very expensive when compared to Ireland.
\end{abstract}

Keywords: SEM; BETTA; simulation model; market design

JEL classification: C63, L94, L98

\section{Introduction}

This paper investigates the price of electricity in Ireland and Great Britain ${ }^{1}$, two very different markets. We compare both wholesale and retail prices during the 2008-2011 period and suggest structural, technological and regulatory characteristics that explain the price differences. We determine how these differences are likely to affect future electricity prices, a worthwhile effort in light of the move towards more renewables and the EU's attempt to integrate electricity markets through the Target Model.

Since the end of 2007 Northern Ireland and Ireland have shared a wholesale electricity market, here referred to as the Single Electricity Market (SEM). The two regulators on the island (the Northern Ireland Utility Regulator and the Commission for Energy regulation, CER) cooperate to regulate the wholesale market through the SEM committee. The SEM has strict rules and is tightly monitored, thereby limiting generators’ opportunities to exploit market power.

Great Britain (GB) and Northern Ireland, as regions of the United Kingdom (UK), share similar and interrelated schemes to encourage renewable electricity generation: the Renewable Obligation

\footnotetext{
${ }^{1}$ In this paper we refer to the Republic of Ireland as "Ireland”. When addressing Ireland and Northern Ireland as a single entity we refer to the island of Ireland. We use Great Britain (GB) to distinguish that part of the UK from Northern Ireland, also part of the UK. While both Northern Ireland and GB are regions of the UK, they have separate regulators: the Office of Gas and Electricity Markets (Ofgem) and the Utility Regulator, respectively.
} 
Certificates (ROCs) and the Northern Ireland ROCs respectively. In Ireland support for renewables is provided by a different mechanism - a feed in tariff (REFIT).

Great Britain faces an uncertain future with respect to electricity prices. Most existing nuclear plants are due to close around the end of the decade and much coal-fired capacity will also close in 2016 as a result of the EU Large Combustion Plant Directive. It is not clear how this obsolete plant portfolio will be replaced and there are concerns that prospective returns from investment under the current market rules may not result in adequate investment (Helm, 2009).

We use information from the transparent market in Ireland to build a benchmark against which to compare market outcomes in Britain. Giulietti et al. (2010) show that the move to a market based on bilateral contracts in GB, combined with other changes in market structure, saw a squeezing of wholesale margins, with profitability being enhanced at the retail end. We confirm these findings and suggest that existing retail margins are generally sufficient to compensate for the lower wholesale prices.

The paper is organised as follows. In Section 2, we examine retail electricity prices in Ireland and GB over the past 30 years. We then compare historical wholesale prices in the two markets in Section 3. Since there is no single official wholesale electricity price for Great Britain, we discuss two estimates of its wholesale price. To measure the cost of generation in the GB market (BETTA), we build a model of BETTA that provides a lower bound for its historical generation costs. Using the same model and imposing identical fuel input prices in BETTA and SEM, we determine how much of the difference between wholesale prices is due to differences in generation technology. Section 4 examines domestic retail prices in detail and discusses some of the drivers of retail margins. Section 5 discusses the likely trend in future prices given our findings and Section 6 concludes.

\section{History}

Over the last 30 years retail electricity prices have generally been higher in Ireland than in the UK. ${ }^{2}$ Figures 1 and 2 show a comparison of the electricity prices (excluding both excise tax and VAT) faced by industry and households in Ireland and GB in nominal euro. These data are taken from the International Energy Agency publication Energy Prices and Taxes, the only source that provides prices back to the 1970s on a consistent basis. To convert the GB prices to euro we use average yearly exchange rates published by Eurostat.

The gap between prices was particularly big in the 1980s, especially for the household sector. This reflected the need in Ireland to fund major investment in the main coal-fuelled generating station. By

\footnotetext{
${ }^{2}$ As Northern Ireland is a small region of the UK we take the UK prices to be representative of the GB market.
} 
the end of the 1990s that station had largely been paid for and investment in Ireland was at a low level.

Figure 1. Industry electricity prices, ex-tax, $€ / \mathrm{kWh}$, nominal

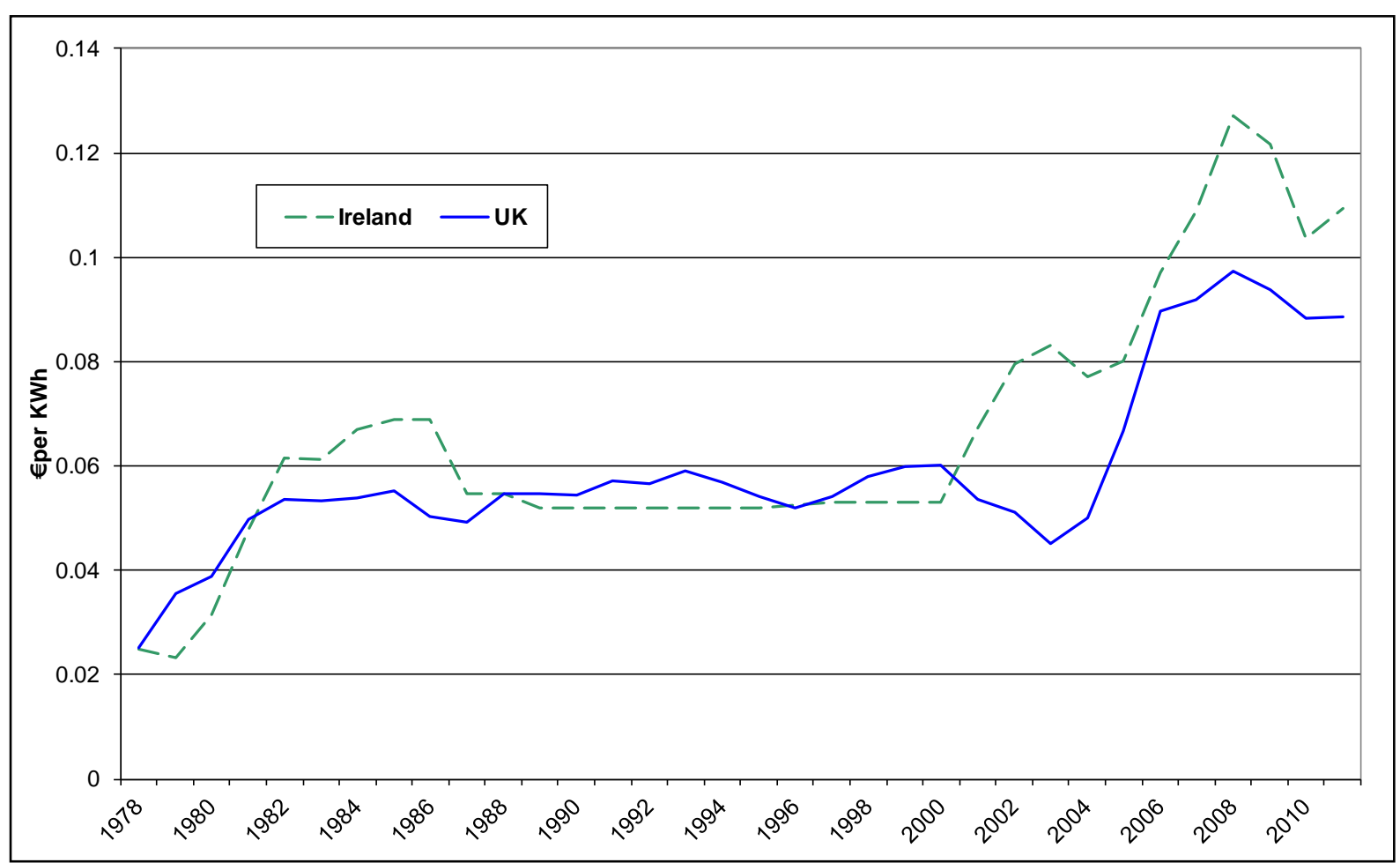

Source: IEA Energy Prices and Taxes, various years

Figure 2. Household electricity prices, ex-tax, $€ /$ kWh, nominal

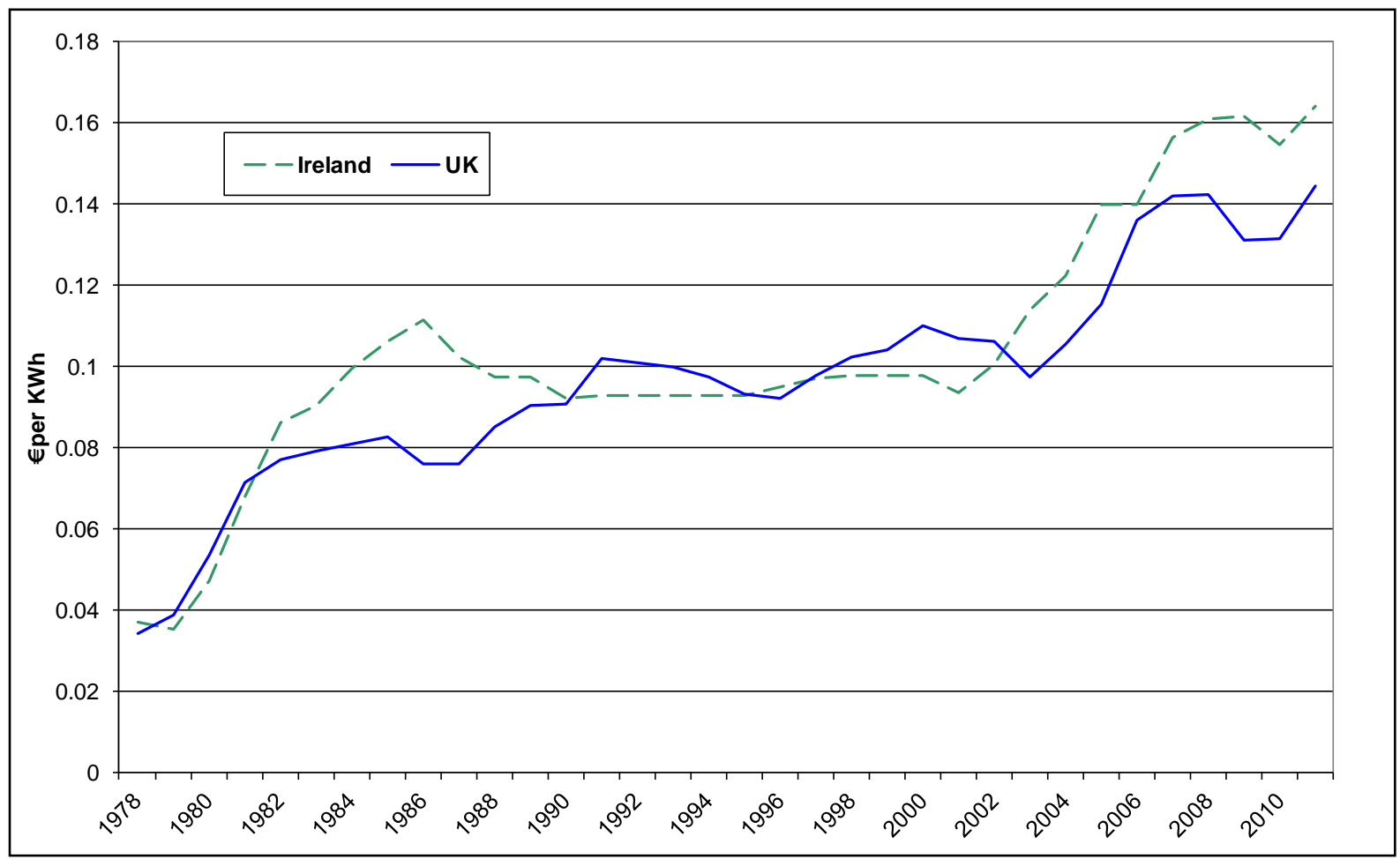

Source: IEA Energy Prices and Taxes, various years. 
Until the late 1990s the state-owned utility, the Electricity Supply Board (ESB), had total responsibility for the sector in Ireland. Over the period 1980-2000, prices were generally based on the average cost of electricity generation. When investment was undertaken this resulted in high prices and when there was a lull in investment the assets were "sweated", with prices falling below long run marginal cost. This approach to pricing was common in regulated utilities (Helm 2004), although it is a suboptimal approach from a wider economic efficiency point of view.

By contrast, in Great Britain following privatisation of the industry and the breakup of the Central Electricity Generating Board (CEGB) monopoly in the early 1990s, there was substantial excess capacity. The transmission and distribution infrastructure was already fully developed and growth in the UK economy in the subsequent period did not result in a major increase in demand. The advent of new more efficient technology using natural gas (combined with low gas prices) saw a "dash for gas" in the 1990s, which further increased capacity. When this resulted in a major drop in utilisation of existing coal-fired plants, which were already fully depreciated, this spare capacity was moth-balled rather than decommissioned. There has consequently been no need for major new investment in generating capacity over the past decade. The result of this excess capacity has been that, over time, electricity prices in the British market did not reflect the long run marginal cost of producing electricity. Given costs sunk in excess generating capacity, generators competed for market share on the basis of short run marginal costs.

Electricity prices in Ireland and GB were also affected by the movement in energy prices. The fall in oil prices and the low gas price in Ireland in the 1990s drove the cost of electricity in Ireland down. The result of the fall in average capital costs and the change in relative prices of fuels meant that in the late 1990s, for a short period, prices in Ireland actually fell below those in GB. However, the rapid rise in gas prices (relative to coal) since 2000, combined with the necessary shift to pricing at long run marginal cost, has seen a substantial wedge open up between Irish and British prices, especially for industrial users.

\section{Wholesale prices}

Comparing wholesale prices in the two systems is not straightforward. The SEM is a mandatory pool market with capacity payments. Wholesale prices for SEM are the sum of the System Marginal Price (SMP), which reflects the marginal cost of generating electricity in the short run, and capacity payments, designed to compensate for the capital cost of building new generation. Capacity payments are allocated on a half-hourly basis, and are larger when the gap between available generation capacity and consumption of electricity is smaller. The SMP and capacity payments for SEM are published by the system operator SEMO (www.sem-o.com) for every half hour. The transparency of the market design facilitates monitoring and evidence indicates that firms have priced at short-run 
marginal cost (Market Monitoring Unit, 2009; Gorecki, 2013). Lyons et al. (2007) showed that the SEM incentivises investment in new generation without rewarding new generators excessively.

It is more difficult to obtain data for the British system. BETTA is an energy-only market and is designed to encourage bilateral trading, for which there is no public information. Most of the transactions take place within vertically integrated firms. The system operator is in charge of the balancing market, which does not provide a unique price signal: there is a buy and a sell price and generators can be on either side of the buy/sell relation. ${ }^{3}$ We use data from Elexon (elexon.co.uk) to determine the balancing or spot price. There are several power exchanges in the BETTA market, each potentially giving rise to a different price. In this study we use data from the APX exchange for electricity futures prices, as it is available for the whole period we cover: 2008 - 2011. The balancing market represents only 1 per cent of total electricity demand, although Bunn and Zachmann (2010) suggest that balancing prices are in line with over-the-counter prices, which account for a further 9 per cent of total volume.

We use two measures of the British wholesale price: the spot market price and a price based on18 month hedged prices. The spot price is calculated from balancing data published by the system operator. ${ }^{4}$ The balancing price is the best available measure of the spot price, but it is not a perfect indicator (see Ofgem, 2013, Appendix 1).

Table 1. Wholesale System Prices in SEM and BETTA, in €/MWh

\begin{tabular}{|c|c|c|c|c|c|}
\hline \multicolumn{4}{|c|}{ SEM } & \multicolumn{2}{|c|}{ BETTA (GB) } \\
\hline Year & SMP & Capacity & Total & Spot & 18 month hedge \\
\hline & & Payments & & & \\
\hline 2008 & 84.2 & 15.7 & 99.9 & 86.4 & 63.0 \\
\hline 2009 & 46.5 & 18.6 & 65.1 & 41.5 & 64.6 \\
\hline 2010 & 56.9 & 15.7 & 72.6 & 48.6 & 53.3 \\
\hline 2011 & 64.9 & 16.2 & 81.1 & 55.2 & 54.4 \\
\hline
\end{tabular}

Note: all prices are average yearly prices, in nominal euro.

Source: authors' elaboration of SEM data from www.sem-o.com, APX data from ICE (www.theice.com) and balancing data from Elexon.co.uk.

\footnotetext{
${ }^{3}$ For more on the British market, see for example Steggals et al. (2011).

${ }^{4}$ We follow Elexon (2013) and use the reverse energy imbalance price in each half hour to identify the market price, which is designed to represent the price that would have emerged on a power exchange market.
} 
The 18-month hedge price is built following the methodology presented in Ofgem (2009b), assuming that generators enter into forward contracts with suppliers and sell their power starting 18 months ahead of the generating period, selling a residual 10 per cent at the spot price. Specifically, we calculate a hedged price per quarter assuming that companies sell 15 per cent of their output in each of the prior 6 quarters and obtain the going forward price at the time. To obtain the annual price we take a weighted average of the quarterly hedged price, where the weights are determined by consumption during the quarter. The price generators obtain for electricity at time $t$ therefore depends in part on the forward price established 18 months prior to t.

BETTA does not feature capacity payments, so generators must recover their long run costs through the energy prices. We therefore compare the sum of SMP and capacity payments in SEM to energy market prices in BETTA. Table 1 reports the prices for all years, transformed into euro.

SEM prices are closely tied to spot fuel and carbon dioxide permit prices, as generators are expected to bid on the basis of these input costs. The strong drop in oil and natural gas prices that occurred in February 2009 translated into lower spot prices in both jurisdictions. Not surprisingly it took a bit longer to emerge in the hedged prices series. In general, however, BETTA prices appear lower than SEM prices. There are several potential drivers of this result. In section 3.2 we consider whether British wholesale prices might actually be too low, in the sense that they are not sufficient to cover long run marginal costs. British prices could also be lower because of a different portfolio of plants. We examine this option in Section 3.3. Before addressing the findings of our simulations, section 3.1 describes the model for BETTA.

\subsection{The Model}

The electricity market model is constructed with PLEXOS. ${ }^{5}$ The PLEXOS modelling tool is used by the CER and the Utility Regulator to validate the Single Electricity Market and has a history of use in Ireland (Commission for Energy Regulation and Utility Regulator 2011). PLEXOS optimises hydro, thermal, renewable and reserves simultaneously. Modelling is carried out using mixed integer linear programming that minimises the cost of generation, including fuel, carbon and start-up costs, while meeting generating plants' technical constraints. PLEXOS reports the shadow price and the uplift for each period. The shadow price can be interpreted as the marginal price of electricity generation or, in other words, the cost incurred to match an incremental change in demand. Any additional fixed and start-up costs are remunerated through the uplift factor.

\footnotetext{
${ }^{5}$ PLEXOS for Power systems. Online at www.energyexemplar.com
} 
The British model is based on the version built in Deane et al. (2013) and uses the Xpress ${ }^{6}$ Mixed Integer Programming solver. We use the list of plants reported in National Grid's demand data and take their types and capacities from the Digest of UK Energy Statistics (DUKES).

To calibrate the model to historical values between 2008 and 2011, we make a few adjustments. We use the half-hourly wind generation series reported by National Grid. This series starts on 5 November 2008. For the period up to 5 November 2008 we used the 2009 wind profile (wind generation divided by installed capacity) and apply it to the 2008 installed wind capacity to estimate the half-hourly wind generation. ${ }^{7}$ Nuclear generation in Britain experienced a number of outages in recent years. We impose the historical annual load factors reported in DUKES, Table 5.10. Finally, a number of coal plants opted out of the Large Combustion Plant Directive (LCPD) and were therefore constrained to operate for no more than 20,000 hours between 2008 and 2015. We limit their yearly availability to the number of hours they actually generated during these four years. ${ }^{8}$ Interconnector flows and pumped storage use are difficult to model accurately. We therefore take demand net of interconnector flows and pumped storage use. The half-hourly values for the interconnectors and pumped storage operations are reported by National Grid. ${ }^{9}$ Transmission constraints are not included in the model and the model therefore reports a single price for the whole market in any given period.

Table 2. Fuel prices in the British market, $€ / M W h$

\begin{tabular}{|c|c|c|c|c|}
\hline & Coal & $\begin{array}{l}\text { Natural } \\
\text { Gas }\end{array}$ & Oil & $\mathrm{CO}_{2}(€ /$ tonne $)$ \\
\hline 2008 & 7.38 & 13.06 & 18.85 & 18.82 \\
\hline 2009 & 6.98 & 12.49 & 19.77 & 13.16 \\
\hline 2010 & 7.72 & 12.53 & 29.90 & 14.31 \\
\hline 2011 & 9.93 & 16.61 & 38.32 & 12.99 \\
\hline
\end{tabular}

Note: average yearly exchange rate used for conversion.

Fuel prices from DUKES. $\mathrm{CO}_{2}$ prices are EUA prices published by Bluenext.

\footnotetext{
${ }^{6}$ FICO Xpress Optimiser. Available online at http://www.fico.com

${ }^{7}$ Dukes reports that the combined onshore and offshore wind load factor was 27.5\% in 2008 and 27.1\% in 2009 based on average yearly installed wind, making the approximation reasonable.

${ }^{8}$ This information is available from the Environment Agency at: http://www.environmentagency.gov.uk/business/sectors/32621.aspx.

${ }^{9}$ http://www.nationalgrid.com/uk/Electricity/Data/
} 
Fuel input prices for Britain come from the quarterly survey of British major power producers published in DUKES. Table 2 states the fuel and $\mathrm{CO}_{2}$ permit prices, expressed as the yearly average in nominal euro per MWh and euro per tonnes of $\mathrm{CO}_{2}$ respectively.

To create a measure of long run marginal costs, in addition to the SMP we need to estimate the British equivalent of the capacity payments. We follow the methodology used by SEM regulators each year. ${ }^{10}$ We build a yearly capacity pot for Great Britain, based on the cost of capital for a best new entrant published by the SEM regulators and the expected tightness of the market, which is a function of plant availability and the level of demand. Our measure may slightly overestimate the payments needed to encourage building of new power plants in Britain if investing in GB is cheaper than in the SEM due to its larger size. Capacity payments are calculated assuming that all thermal plants are available to generate about 90 per cent of the time. This reflects best practice levels, not historical plant availability. Nuclear plants are assumed to be available about 70 per cent of the time. The forced outage probability is set at around 5 per cent across plants.

The size of the capacity pot is somewhat sensitive to availability and forced outage assumptions. If plant availability were set lower, capacity payments would be higher. As we note later, reasonable variations in capacity payments for BETTA do not significantly affect our conclusions.

\subsection{BETTA and long run marginal costs}

Table 3 reports the estimated SMP, disaggregated into shadow price and uplift, and capacity payments for BETTA. The average price is weighted by demand.

The system prices we report are lower bounds of the historical generation costs, as the PLEXOS model determines the least cost solution to meet demand. The actual BETTA market, based on bilateral contracts, can deviate significantly from an optimal dispatch framework and might therefore generate more with plants that are relatively more costly. We find, for example, that coal generation for 2009-2011 has been much higher than our model would predict given the fuel prices that occurred. ${ }^{11}$ This underlines the fact that historical costs of wholesale electricity are likely to be higher than our estimates. Despite this, the SMP we calculate exceeds the hedged wholesale price for all years except 2009.

Adding the estimated capacity payments per MWh, the Long Run Marginal Cost (LRMC) is always higher than the hedged price. Note that the result would hold even if capacity payments were half the

\footnotetext{
${ }^{10}$ See http://www.allislandproject.org/en/cp_decision_documents.aspx

${ }^{11}$ Results on generation by fuel type are not reported but are available from the authors.
} 
size we estimate here. If we were to use the spot price reported in Table 1 the general conclusion would not change. Except for 2008, spot prices are significantly lower than the estimated LRMC.

The estimated cost of an additional unit of electricity, measured by the shadow price, is also unexpectedly higher than the reported spot price for most years, particularly for 2009. This might be due to several factors. First of all, as discussed previously, the balancing price does not measure the spot price perfectly. Second, there are approximations in the simulated costs of each plant, both in terms of fuel costs (which are averages across plants and over time) and operation and maintenance costs.

Although the simulation results are necessarily approximations, our findings provide evidence that the British wholesale market might be underpricing electricity. The GB market might encounter difficulties securing replacements for the generating capacity to be retired over the coming decade (Helm, 2009). We discuss this in more detail in Section 5.

Table 3. British estimated wholesale costs, €/MWh

\begin{tabular}{|c|c|c|c|c|c|c|}
\hline \multirow{3}{*}{ Year } & \multicolumn{5}{|c|}{ Model Results } & \multirow{3}{*}{$\begin{array}{l}\text { Historical Data } \\
\text { Hedged price }\end{array}$} \\
\hline & Shadow & Uplift & Total & Capacity & Total & \\
\hline & Price & & SMP & Payments & LRMC & \\
\hline 2008 & 61.3 & 9.4 & 70.7 & 15.1 & 85.8 & 63.0 \\
\hline 2009 & 46.4 & 10.3 & 56.8 & 16.4 & 73.2 & 64.6 \\
\hline 2010 & 51.0 & 11.0 & 62.0 & 16.0 & 78.0 & 53.3 \\
\hline 2011 & 56.2 & 10.4 & 66.6 & 15.4 & 82.0 & 54.4 \\
\hline
\end{tabular}

Note: model numbers are all averages weighted by period demand. For historical data, see notes for Table 1.

The low LRMC does not mean that current generators are making losses. The industry is dominated by vertically integrated utilities, so profitability should be assessed across the range of activities undertaken by these firms. Integrated energy utilities, while not receiving adequate remuneration from the wholesale market, derive exceptional profits from their retail operations, which could incentivise new investment (Giulietti et al.,2010). We explore retail prices further in Section 4.

\subsection{The impact of technology differences}

To examine the effect of technology differences on prices, we impose the same input prices shown in Table 2 on both SEM and BETTA. Each plant in SEM is modelled based on the public parameters 
reported yearly by the CER (see www.allislandproject.org). To be consistent with the modelling of BETTA, we simulate demand net of interconnection flows and use historical wind generation series.

On this basis, in 2008 estimated British wholesale prices would have been lower than SEM prices by $€ 9 / \mathrm{MWh}$, or about 11 per cent. Constraints on coal plants and outages of nuclear plants caused the plant portfolio to become progressively more expensive in GB and by 2010 the cost of electricity was lower in Ireland. The result is also driven by changes in the relative cost of coal with respect to natural gas. As natural gas prices decreased with respect to coal, the cost of generating electricity in Ireland decreased with respect to Great Britain. This trend reversed in 2011 contributing to the price convergence with BETTA. Additionally, in 2011 the SEM experienced large outages in the interconnector with Scotland. Table 4 summarises the results.

Table 4. BETTA and SEM SMP prices, with equal fuel input costs, €/MWh

\begin{tabular}{llll}
\hline & BETTA & SEM & Difference \\
\cline { 2 - 4 } 2008 & 70.7 & 79.7 & 9.0 \\
2009 & 56.8 & 58.1 & 1.3 \\
2010 & 62.0 & 57.7 & -4.3 \\
\hline
\end{tabular}

Source: PLEXOS model results

The importance of technology in explaining price differences is less than previously estimated (Devitt et al. 2011) because here we account for the limitations on the availability of coal and nuclear plants in GB.

\section{Domestic retail prices}

Comparable information on domestic retail prices is available for the two jurisdictions. Eurostat reports electricity prices by bands of consumption. ${ }^{12}$ We take the $2500-5000 \mathrm{KWh}$ per year band as representative of the domestic sector. Average domestic consumption was $4150 \mathrm{kWh}$ for all domestic households in GB in 2009 (and 3800kWh/year for households on standard meters, which accounted

\footnotetext{
${ }^{12}$ Because of issues with data availability we use IEA data for comparisons over long periods. The more comprehensive Eurostat data are preferred for the detailed comparisons in this section.
} 
for more than 80 per cent of total households). ${ }^{13}$ In Ireland average consumption for all domestic households was about 5000kWh/year in 2011. ${ }^{14}$

To provide electricity to final consumers, suppliers have to pay for the wholesale electricity price, balancing costs, transmission and distribution charges, environmental charges, and the costs they encounter metering and billing electricity usage.

We have already discussed wholesale prices extensively. In this section, we take the hedged price presented in Section 3 as the representative price for Britain. Balancing costs are costs incurred to maintain the reliability of the system. In some instances, for example in the presence of congestion on the transmission lines, the system operator has to deviate from the preset dispatch schedule and constrain some plants on or off. Balancing payments cover the costs of these constraints. In Ireland balancing charges per MWh are determined every year by the CER. For GB, they are published on an hourly basis by National Grid. In order to reach final consumers, electricity has to travel through large transmission and smaller distribution lines.

Environmental costs include the Public Service Obligation in Ireland (although the PSO supports non renewables as well, such as peat plants). In GB they consist of Renewable Obligation Certificates (ROCs) and the Carbon Emissions Reduction Target (CERT).

Table 5 presents a breakdown of these costs. Balancing costs are averages per unit of final demand. Transmission, distribution and environmental costs for GB are calculated on the basis of their shares in the overall bill published by Ofgem (2008, 2009a). Costs for 2010 and 2011 are based on the information reported by the Committee on Climate Change (2011a and 2011b). For Ireland, they come from the official tariffs imposed by the CER for standard electricity users, assuming a yearly consumption of 3.3MWh, weighted by monthly generation when the tariffs do not coincide with calendar years. ${ }^{15}$ Distribution costs are averaged by the share of urban versus rural households reported in the 2011 Census (64 per cent urban and 32 per cent rural). This is necessary since electricity prices are two-part tariffs and there is a different fixed fee for rural versus urban areas.

\footnotetext{
${ }^{13}$ See Table 2 in: http://www.decc.gov.uk/assets/decc/11/stats/publications/energy-trends/articles/4782-subnat-

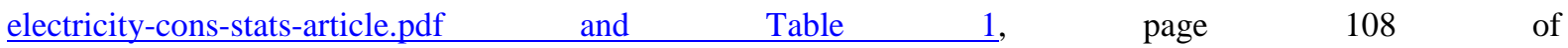
http://www.decc.gov.uk/assets/decc/11/stats/publications/energy-trends/3917-trends-dec-2011.pdf

${ }^{14}$ Based on 2011 electricity consumption information from the SEAI Energy Balance and the number of households from the 2011 Census.

15 Documents on Irish transmission and distribution tariffs can be found respectively at http://www.allislandproject.org/en/transmission_decision_documents.aspx and http://www.cer.ie/en/electricitydistribution-network-decision-documents.aspx.
} 
Table 5. Retail costs and margins for domestic consumers, $€$ /MWh, nominal prices

\begin{tabular}{|c|c|c|c|c|c|c|c|c|}
\hline & \multicolumn{2}{|c|}{2008} & \multicolumn{2}{|c|}{2009} & \multicolumn{2}{|c|}{2010} & \multicolumn{2}{|c|}{2011} \\
\hline & GB & IRL & GB & IRL & GB & IRL & GB & IRL \\
\hline Retail Price & 146.2 & 167.5 & 137.0 & 171.2 & 135.1 & 162.1 & 143.7 & 175.6 \\
\hline Wholesale Price & 63.0 & 99.9 & 64.6 & 65.1 & 53.3 & 72.6 & 54.4 & 81.1 \\
\hline Balancing costs & 1.5 & 3.3 & 1.4 & 2.8 & 1.3 & 3.1 & 1.4 & 5.4 \\
\hline \multicolumn{9}{|c|}{ PSO/Environmental } \\
\hline costs & 9.2 & 0.9 & 11.5 & 5.3 & 13.5 & 8.9 & 16.1 & 6.5 \\
\hline Transmission & 4.6 & 6.6 & 4.3 & 6.9 & 5.7 & 7.7 & 6.1 & 8.1 \\
\hline Distribution & 23.1 & 42.6 & 21.6 & 41.5 & 22.7 & 51.3 & 25.3 & 50.9 \\
\hline Retail Margin & 44.7 & 14.1 & 33.5 & 49.7 & 38.6 & 18.4 & 40.5 & 23.6 \\
\hline
\end{tabular}

Note: Estimates in italics. Domestic price from Eurostat. Simple average of 6-month reported data; Price for band DC (between 2500MWh and 5000MWh consumption yearly), excluding VAT.

Breakup of costs: authors' calculations based on OFGEM and CER data.

When fixed costs are present, averages taken for a consumer using 3.3 MWh/year.

There are a few aspects of Table 5 that are striking. First of all, retail margins in Great Britain are typically much larger than in Ireland. In light of the findings in the previous section, this is not surprising. Vertically integrated electricity companies are recouping part of the costs they incur generating electricity on the retail market. The net impact on final consumers is a priori unclear. Vertical integration is likely to decrease wholesale prices, as we saw in this analysis (see also Bushnell et al., 2008 who study US markets). In principle one might also expect large retail margins to encourage new entry into the retail market. However, in practice retailers must build a customer base and find generators willing to sell to them. If this is difficult because most electricity companies are vertically integrated, entry in the retail sector might be limited and average consumer prices might be higher than they need be. For a description of how vertical integration can limit competition, see for example Rey and Tirole (2007).

The effect of vertical integration in the British market is examined in Giulietti et al. (2010). They find a substantial impact arising from the strong retail position of integrated firms and cite evidence of large increases in supplier profitability during the time vertical integration developed. Vertical ties had been eliminated at the onset of deregulation in the early 1990s (Wolfram, 1999). Giulietti et al. 
(2005) show that incumbent electricity providers maintained significant market power in the residential sector. After liberalisation only a minority of consumers took full advantage of retail competition by switching suppliers, and switching repeatedly (Ipsos Mori, 2013). Even those who switched did not necessarily move to the cheapest supplier (Wilson and Waddams Price, 2010). This lead to higher average retail margins for suppliers in GB. Entry with a new integrated firm is unlikely, unless by takeover, due to the effort needed to build a customer base. The overall effect of vertical integration is to protect incumbents from new entry and maintain high profit margins.

The second issue that arises from Table 5 is the high cost of distribution for Irish consumers. Most of it can be ascribed to the sparser population in Ireland versus Great Britain. Ireland has 82 metres of distribution per customer on average (Commission for Energy Regulation 2010). For Great Britain the network with the longest per capita distribution is Northern Scotland at 63 metres per customer. Elaboration of data in Ofgem (2012) shows that the British average was 27 metres per customer.

Table 6. Share of renewables in final electricity demand, \%

\begin{tabular}{lcccc}
\hline & 2008 & 2009 & 2010 & 2011 \\
\cline { 2 - 5 } Great Britain & 6.2 & 7.6 & 7.6 & 9.8 \\
Ireland & 13.4 & 16.3 & 14.7 & 21.8 \\
\hline
\end{tabular}

Source: authors' elaboration of data from Dukes and Restats (GB) and Energy Balances (Ireland)

Finally, environmental costs appear to be substantially higher in BETTA than in Ireland even though the penetration of renewables in electricity generation is about half that of Ireland, as shown in Table 6. In part in reaction to these high costs, the Department of Energy and Climate Change (2012) is moving away from ROCs and adopting feed-in-tariffs.

\section{Future Prices}

The wholesale price in Great Britain for the 2008 to 2011 period was probably too low, insufficient to remunerate the long-run marginal cost of generating electricity. This conclusion is similar to that of other studies (Helm, 2009). The British market needs substantial new investment in generation to continue enjoying a reliable electricity supply over the coming decade. New generation will only take place if investors are confident they will be adequately remunerated. In recent years the move has been in the opposite direction, with natural gas plants being mothballed (Royal Academy of Engineering, 2013).

The Department of Energy and Climate Change (2012) is considering a capacity mechanism to encourage new investment in generation. This would increase final prices.

If we substitute our estimate of long run costs from Table 3 in the calculation of retail margins, we obtain the results shown in Table 7. 
Table 7. Retail margin in Great Britain, with estimated LRMC, €/MWh

\begin{tabular}{lcccc}
\hline & 2008 & 2009 & 2010 & 2011 \\
\cline { 2 - 5 } Retail Price & 146.2 & 137.0 & 135.1 & 143.7 \\
LRMC & 86.9 & 72.4 & 78.0 & 82.0 \\
Other costs & 38.5 & 38.9 & 43.2 & 48.8 \\
Retail Margin & 20.8 & 25.7 & 13.9 & 12.9
\end{tabular}

Source: Model results and DUKES. See notes to Table 3 and Table 5. Estimated values in italics.

For 2008 and 2009 there was enough revenue in the system to encourage new generation (i.e. to cover both short run and capital costs). The margin decreased in 2010 and 2011. The lower retail margin of €13/MWh to €14/MWh does not deviate substantially from the 2010-2011 average in Ireland, which was about $€ 16 / \mathrm{MWh}$. Whereas some increase in generator returns might be needed to encourage new investment, it should not be very large given these estimated retail margins. However, while the revenue may be there to finance such new investment, the incentives for the firms may well be to delay such investment, maintaining higher operating profits.

The challenge for GB lies in designing mechanisms that increase returns to generation, and therefore incentives to invest, while limiting retail margins. It is difficult to envisage how this can take place within the current British market structure, with a vertically integrated industry, bilateral contracts and limited regulation. Bilateral contracts do not per se lead to higher prices and are compatible with the EU Target Model. ${ }^{16}$ There is, however, some evidence that centralised markets are more efficient. Mansur and White (2012) find that when the Midwest of the US moved away from bilateral markets to join a centralised auction market, trade (and dispatch efficiency) greatly increased.

Whereas a complete analysis of the optimal market design for GB exceeds the scope of this paper, we can make a few comments based on the comparison with SEM. With integrated utilities, volatility in the wholesale market can be hedged within the firm, resulting in a more stable price for consumers. However, this is also possible with a pool where generators and suppliers can also use contracts for difference to hedge price risk for consumers.

When SEM was set up it had three main goals: deliver electricity efficiently, while reducing market power and encouraging entry. These goals have been largely achieved (see Gorecki, 2013 and references cited therein). In the past few years many new thermal plants have been commissioned and new market participants have entered the market (mostly through acquisitions of existing plants). The

\footnotetext{
${ }^{16}$ For details on the Target Model, see for example Gorecki (2013).
} 
transparency of the central market design means that it is easy to monitor firms' behaviour and prevent abuses.

Regulation is an important component of the SEM. Centralised pool markets can exhibit market power problems. This was the case with the pool market in England and Wales (Wolfram, 1999), even after the original incumbents were forced to divest some of their assets (Sweeting, 2007). When entry is difficult and capacity is limited transparency can increase the incentive to collude, as shown by Kühn (2012). The conclusion is that even liberalised markets may benefit from strong regulatory oversight.

A second important issue for public policy is the range of mechanisms used to promote renewable generation. In Great Britain the imposition of a Renewables Obligation (ROCs) is significantly more costly than it need be (Helm, 2010). McIlveen (2010) estimates that the implied carbon price under the scheme is $£ 130$ per tonne of carbon dioxide. The commitment to develop large volumes of offshore wind and wave power in the future will be even more expensive. Moreover, the government has recently declared that it has agreed to guarantee the price of a new $3200 \mathrm{MW}$ nuclear plant at Hinkley Point for 35 years. The price guarantee would be equal to $£ 92.5$ per MWh (€109/MWh at average 2013 exchange rates) for a single nuclear plant, decreasing to £89.5 per MWh (€105/MWh) if an additional nuclear plant is built by EDF. The EU has opened an investigation to determine if the agreement complies with EU rules on state aid. ${ }^{17}$

Higher levels of wind are also likely to affect the returns on investment of thermal plants, which might be a concern in any market where substantial investment is needed for system reliability (Di Cosmo and Malaguzzi Valeri, 2012). This affects all jurisdictions, but is especially true in GB, where the worst case scenario for consumers would be a high expenditure on renewable support paired with additional support for thermal plants and a continuing high level of retail margins.

\section{Conclusions}

This paper examined the wholesale and retail prices in Ireland and Great Britain. The British market is not price transparent, so the results presented here are approximations of true prices and costs. That said, our findings strongly suggest that wholesale prices in Great Britain are much lower than in Ireland. Differences in prices between the SEM and BETTA are not primarily caused by technological differences. In the Irish case the prices charged on the wholesale market reflect the short-run marginal cost and, taken together with the capacity payments, provide generators with a return approximating

\footnotetext{
${ }^{17}$ Details available at https://www.gov.uk/government/news/initial-agreement-reached-on-new-nuclear-powerstation-at-hinkley. Information on the European Commission investigation is at: http://europa.eu/rapid/pressrelease_IP-13-1277_en.htm.
} 
their long-run marginal cost of production. Using a model that commits and dispatches generating plants optimally, we show that the wholesale price in Great Britain is not sufficient to cover long run generation costs. The BETTA model is thus not a sustainable long-term model. In fact special provision had to be made to ensure new investment in a nuclear plant at Hinkley Point to maintain sufficient capacity. If new investment is to be incentivised by the market a move to some form of remuneration for capacity seems inevitable.

For GB our analysis suggests that total electricity costs are sufficient (or close to being sufficient) to remunerate all aspects of providing electricity, but currently all the profits are extracted at the retail stage, with high retail margins.

By keeping the wholesale price of electricity below long-run marginal cost incumbents can prevent new entry by generators. Vertically integrated companies use the returns on the retail market in part to finance generation costs. However the incentive to invest in new plant is weak. For existing firms, investing in more generation would reduce the per unit profits they receive. New firms have difficulty entering exclusively at the wholesale level for two main reasons. First, wholesale prices are low and second, it is difficult to build a viable customer base in a market that is dominated by vertically integrated firms.

In the Irish market, by contrast, there has been extensive new entry resulting in significant construction of new thermal generating plants without ad-hoc intervention by the regulatory authorities.

The GB market could (and should) be restructured to allow generators to be fairly remunerated for their costs while simultaneously decreasing retail margins. It is difficult to envisage how this could be achieved without changing a system based on vertically integrated firms, bilateral contracts and limited regulation. However, increasing returns to generators without decreasing retail margins would put an excessive burden on final consumers.

Upward pressure on prices is likely in the future. Both jurisdictions aim to increase the share of renewables in electricity generation and this will increase costs. The cost of supporting renewables per MWh of electricity consumed is, however, much higher in GB, even though renewables account for a smaller share of overall consumption. There is therefore scope to decrease the cost of environmental measures while achieving the same environmental impact. The move in the UK to feed-in tariffs and away from ROCs might help.

Acknowledgments: FitzGerald, Malaguzzi Valeri and Walsh are grateful for the support of the ESRI Energy Policy Research Centre. Deane is grateful of the support of the Environmental Protection Agency under 'TIMES Phase II' funding. We thank Andrew Self for useful discussions on British 
wholesale prices and Adrienne Costello, Paul Gorecki, Kevin Hagan, Niall Power for comments. Comments from two anonymous referees improved the paper. The usual disclaimer applies.

\section{References}

Bunn, D. and G. Zachmann (2010) Inefficient arbitrage in inter-regional electricity transmission, Journal of Regulatory Economics, 37, 243-265.

Bushnell, J., Mansur, E. and C. Saravia (2008) Vertical Arrangements, Market Structure, and Competition: An Analysis of Restructured US Electricity Markets, American Economic Review, 98(1), 237-66

Commission for Energy Regulation (2010) Factsheet: electricity prices in Ireland, CER 10062

Commission for Energy Regulation and Utility Regulator (2011). Validation of market simulation software in SEM to end 2012, SEM-11-072

Committee on climate change (2011a) Energy prices and bills - impacts of meeting carbon budgets, December 2011

Committee on climate change (2011b) Household energy bills - impacts of meeting carbon budgets, December 2011

Deane, P. Driscoll, A. O Gallachóir, B. (2013). Quantifying the Impacts of National Renewable Electricity Ambitions using a North-West European Electricity Market Model. EEM13 (In Review)

Department of Energy and Climate Change (2012) Electricity market reform: policy overview, The Stationary Office

Devitt, C., S. Diffney, J. FitzGerald, L. Malaguzzi Valeri, A. Tuohy (2011) Goldilocks and the Three Electricity Prices: Are Irish Prices “Just Right”?, ESRI WP 372

Di Cosmo, V. and L. Malaguzzi Valeri (2012) The incentive to invest in thermal plants in the presence of wind generation, ESRI WP 446

Elexon (2013) Imbalance pricing guidance: a guide to electricity imbalance pricing in Great Britain, accessed January 2014: http://www.elexon.co.uk/wp-content/uploads/2013/11/imbalance_pricing_guidance_v5.0_cgi.pdf

Giulietti, M., L. Grossi, and M. Waterson (2010), "Price Transmission in the UK Electrical Market: was NETA Beneficial?” Energy Economics, 32(5), 1165-1174

Giulietti, M., C. Waddams-Price, and M. Waterson (2005), Consumer Choice and Competition Policy: a Study of UK Energy Markets, Economic Journal, 115, 949-968

Gorecki, P. (2013) Ensuring compatibility of the all-island electricity system with the target model: Fitting a square peg into a round hole?, Energy Policy, 52, 677-688

Helm, D. (2004) Energy the State, and the Market: British Energy Policy since 1979, Oxford University Press

Helm, D. (2009) Infrastructure investment, the cost of capital, and regulation: an assessment, Oxford Review of Economic Policy, Volume 25, Number 3, 2009, pp.307-326

Helm, D. (2010) Government failure, rent-seeking, and capture: the design of climate change policy, Oxford Review of Economic Policy, Volume 26, Number 2, 2010, pp. 182-196

Ipsos Mori (2013) Customer Engagement with the energy market - Tracking survey 2013: report prepared for Ofgem, accessed Jan. 2014 at www.ofgem.gov.uk/ofgem-publications/74756/customer-engagement-energymarket-tracking-survey-2013.pdf

Kühn, K. (2012) How market fragmentation can facilitate collusion, Journal of the European Economic Association, 10(5), pp. 1116-1140

Lyons, S., J. FitzGerald, L. Malaguzzi Valeri, N. McCarthy and R.S.J. Tol (2007) Preserving electricity market efficiency while closing Ireland's capacity gap, special article in Quarterly Economic Commentary, Fall 2007

Mansur, E. and M. White (2012) Market organization and efficiency in electricity markets, unpublished results 
Market Monitoring Unit (2009) Single electricity market, Public report 2009, SEM/09/039, available at: www.allislandproject.org/GetAttachment.aspx?id=75944418-e3ed-4e72-806d-4cbc0880c6a6

McIlveen, R. (2010), Cutting the Cost of Cutting Carbon, in S. Less ed. Greener, Cheaper, London, Policy Exchange.

National Competitiveness Council (2009) Statement on Energy, Dublin, October 2009.

Ofgem (2008) Household energy bills explained, updated, Factsheet 66, January 2008

Ofgem (2009a) Household energy bills explained, Updated, Factsheet 81, August 2009

Ofgem (2009b) Quarterly wholesale/retail price report, May 2009

Ofgem (2012) Electricity Distribution Annual Report for 2010-11, ref 46/12

Ofgem (2013) Open letter: Update on Electricity Balancing Significant Code Review and new process to review Future Trading Arrangements, February 2013

Rey, P. And J. Tirole (2007). A Primer on Foreclosure. In Handbook of Industrial Organization, Vol. 3, ed. Mark Armstrong and Robert H. Porter, 2145-2220. New York: Elsevier.

Royal Academy of Engineering (2013) GB electricity capacity margin: a report by the Royal Academy of Engineering for the Council for Science and Technology, October 2013

Steggals, W., R. Gross and P. Heptonstall (2011) How high wind penetrations will affect investment incentives in the GB electricity sector, Energy Policy, 39(3), 1389-1396

Sweeting, A. (2007) Market power in the England and Wales wholesale electricity market 1995-2000, The Economic Journal, 117 (April), 654-685

Wilson, C. and C. Waddams Price (2010), Do consumers switch to the best supplier? Oxford Economic Papers, $62,647-668$

Wolfram, C. (1999) Measuring duopoly power in the British electricity spot market, American Economic Review, 89(4), 805-826 